\title{
Protamine Ratio as Predictor of the Fertility Potential of Sperm by Couple Undergoing ICSI
}

\author{
Houda Amor ${ }^{1,2}{ }^{\mathbb{D}}$, Ali Zeyad ${ }^{1}$, Mohamed Sobhy Bakry ${ }^{3}$, Al Mandouh Hussien Bosilah ${ }^{3}$, Habib Ben \\ Ali $^{2}$, Mohamed Eid Hammadeh ${ }^{*}$ (D)
}

\begin{abstract}
Objectives: The present study aimed to measure the protamines P1 and P2 concentrations, standard sperm parameters, and also DNA fragmentation and condensation. In addition, the correlations between the above-mentioned variables and the P1/P2 ratio were explored in order to find out whether the ratio could be used as a biomarker for semen quality.

Materials and Methods: A total of 272 semen samples were divided into 3 P1/P2 ratio groups: G1 as low ( $<0.8)$, G2 as normal (0.81.2 ), and G3 as high (>1.2) ratios. DNA fragmentation and condensation were evaluated by TUNEL and CMA3 (chromomycin $\left.A_{3}\right)$ assays and protamine levels (P1 and P2) were measured using acid urea polyacrylamide gel (AU-PAGE) electrophoresis and western blot (WB).

Results: In G1, CMA3 positive and DNA fragmentation index (DFI) were negatively correlated $(\mathrm{r}=-0.371, P=0.001)$. In addition, $\mathrm{P} 1 / \mathrm{P} 2$ ratio had a positive correlation with DFI $(\mathrm{r}=0.652, P=0.001)$; however it had a negative association with CMA3 $(\mathrm{r}=-0.623$, $P=0.001)$. Moreover, G2 demonstrated positive correlations between sperm concentration and $\mathrm{P} 1(\mathrm{r}=0.257, P=0.011)$ and $\mathrm{P} 2$ $(\mathrm{r}=0.277, P=0.006)$, progressive motility, and $\mathrm{P} 1(\mathrm{r}=0.352, P=0.001)$. The $\mathrm{P} 2$ was positively correlated with progressive motility $(\mathrm{r}=0.380, P<0.01)$. Besides, a positive relationship was found between $\mathrm{P} 1 / \mathrm{P} 2$ ratio and CMA3 $(\mathrm{r}=0.333, P=0.001)$. In contrast, normal morphology showed a negative association $(P<0.05)$ with P1 $(r=-0.206)$ and P2 $(r=-0.208)$. Meanwhile, there was a negative correlation between P1 and DFI $(\mathrm{r}=-0.207, P=0.041)$ as well. Finally, in $\mathrm{G} 3$, negative correlations were also observed between P1 and normal morphology $(\mathrm{r}=-.283, P=.027)$ and also $\mathrm{P} 1 / \mathrm{P} 2$ ratio and $\mathrm{P} 2(\mathrm{r}=-0.372, P=0.003)$ while DFI showed a positive correlation with CMA3 ( $\mathrm{r}=0.299, P=0.019)$.

Conclusions: The results revealed that P1/P2 ratio affected DNA integrity. Therefore, it was found that it could play a crucial role in human sperm quality and function and thus might be used as a predictor of fertility in assisted reproductive technology (ART) treatments.

Keywords: Infertility, Sperm DNA, TUNEL, CMA3, Protamine
\end{abstract}

\section{Introduction}

Infertility is defined as the inability of a healthy couple to conceive after 12 months of regular, unprotected intercourse (1). Male infertility accounts for $40 \%-50 \%$ of infertility and may be caused by numerous factors including genetic causes, poor semen quality, medical disease, hormone aberrations, or it may be idiopathic (2).

Recently, a large number of cases have been overcome with assisted reproductive technologies (ARTs). Intrauterine insemination (IUI) is usually used as a first choice for the treatment of ovulatory dysfunction, minimal endometriosis, unexplained subfertility, and milder forms of male subfertility. Following a mild controlled ovarian stimulation, prepared semen is deposited into the woman's uterus. In vitro fertilization (IVF) is a second procedure where oocytes are fertilized by sperm in vitro (3). Two to 5 days later, the pre-embryo is placed in the woman's uterus. In intracytoplasmic sperm injection (ICSI), nearly the same principles are followed, but a single spermatozoon is selected and directly injected into cytoplasm of the oocyte. Some cases are successful and lead to the birth of a healthy baby. In other cases, embryos may not develop (i.e., they are arrested) $(4,5)$. There are many reasons and explanations for this failure including female inability to support the development, but it is clear that the normal constitution of the male genome, which is injected into the oocyte, is of crucial importance for development of a healthy embryo.

The sperm epigenome is unique and highly specialized because of the unique nature and function of the sperm and also diverse requirements for successful fertilization. Due to the need for better sperm quality, for example, motility, the sperm chromatin must be compacted and highly organized. During spermatogenesis, the chromatin in the sperm head is packaged tightly by the replacement of most histones with 2 types of protamines (i.e., 1 and 2).

Protamines which are small charged alkaline proteins, contain positively charged arginine amino acids that can 
bind to the negatively charged phosphorus in DNA (6). The interaction between positively charged arginine fragments and DNA backbone lead to tight coiling of the DNA, causing it to nearly appear hidden in the protamine; this structure is known as a toroid (6). Therefore, in humans, most of the sperm genome is packaged by protamines instead of histones (7). However, in fertile males, between $5 \%$ and $15 \%$ of the spermatozoa (SPZ) chromatin remains bound to histones rather than protamines (8-11).

It has been demonstrated that a relatively normal proportion of the 2 protamines in humans ranges between 0.80 and 1.20 (12). The protamine ratio can be decreased $(<0.8)$ or increased $(>1.2)$ in sub-fertile patients $(12)$. Other researchers have found a high association between the presence of an altered protamine ratio and altered sperm parameters like sperm concentration, motility, and morphology $(13,14)$.

Furthermore, a number of studies have demonstrated that protamine deficiency could also deteriorate chromatin tight packaging and increase susceptibility to external stress, which can cause a high risk of elevated sperm DNA damage $(15,16)$. There is also conflicting evidence concerning the relationship between sperm DNA fragmentation and fertilization rates following IVF and ICSI. Thus, the aims of the present study were to determine protamine 1 and 2 values, $\mathrm{P} 1 / \mathrm{P} 2$ ratio, standard sperm parameters, chromatin condensation, and DNA integrity; the correlation between the $\mathrm{P} 1 / \mathrm{P} 2$ ratio and the other investigated parameters were also focused on. Finally, it was aimed to determine whether the $\mathrm{P} 1 / \mathrm{P} 2$ ratio could be used as a predictor of sperm quality.

\section{Materials and Methods}

Study Population

Semen samples $(\mathrm{N}=270)$ were randomly collected from male partners of the couples undergoing ICSI treatment at the reproduction and andrology laboratory at the Department of Obstetrics and Gynaecology, University of Saarland, Homburg/Saar, Germany.

The inclusion criteria of the patients were as follows: males who did not have cryptorchidism, present or past cancer treatment, genetic abnormalities such as Klinfelter syndrome or Y-chromosome microdeletion, hypogonadotrophic hypogonadism, drug abuse, varicocele, and/or recent fever episode, and female partners without any history of female-related cause of subfertility (endometriosis, tubal occlusion, or ovulatory disturbance), and no surgical or medical infertility treatment in the last 3 months before undergoing ICSI.

Sperm Collection and Processing

All the semen samples were obtained from the participants through masturbation and then they were collected into sterile containers after at least 3 days of sexual abstinence. The samples were allowed to liquefy for 30 minutes and then were immediately processed. Next, the semen samples were analysed for primary semen parameters such as volume, $\mathrm{pH}$, viscosity, sperm concentration, agglutination, motility, viability, and morphology according to World Health Organization (WHO) guidelines (17).

Sperm morphology was classified according to the strict criteria described by Kruger et al (18). Additionally, seminal smears were stained with Papanicolaou test and analysed accordingly. A total of 100 SPZ were examined per slide using bright field illumination with a magnification of $100 \times$ with oil immersion. The rest of the semen samples were stored at $-20^{\circ} \mathrm{C}$ until the assay was performed (within 3 months).

Sperm Chromatin Condensation ( $\mathrm{CMA}_{3}$ Assay)

Sperm chromatin condensation was assessed using the $\mathrm{CMA}_{3}$ assay, as described by Hammadeh et al (19), with some modifications. Semen sample smears were prepared using $10 \mu \mathrm{L}$ of sperm suspension on microscope slides and allowed to air dry. The smears were fixed in 3:1 methanolglacial acetic acid ratio at $4^{\circ} \mathrm{C}$ for 30 minutes and were allowed to air dry at room temperature (RT). Then, 50

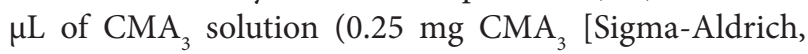
Darmstadt, Germany] in $1 \mathrm{ml}$ phosphate-buffered saline (PBS)) was added to each slide and the slides were coated with cover slips before being incubated in the dark for 30 minutes at RT. The slides were rinsed in PBS buffer and mounted with 1:1 (v/v) PBS/glycerol ratio and allowed to air dry for 1 hour.

A total of 200 SPZ were analysed on each slide using the fluorescence microscope BH2-RFCA (Olympus, Japan) with a green fluorescence filter to distinguish the SPZ that stain bright green ( $\mathrm{CMA}_{3}$-positive) from those that stain a dull green ( $\mathrm{CMA}_{3}$-negative).

\section{Sperm DNA Integrity TUNEL Assay}

The terminal deoxyribonucleotidyl transferase-mediated dUTP nick end labelling (TUNEL) assay was performed using an in situ cell death detection kit according to the manufacturer's instructions (Sigma-Aldrich) with some modifications as described by Borini et al (20). The smears were fixed with $4 \%$ paraformaldehyde-PBS, $\mathrm{pH}=7.4$, at RT for 2 hours and washed with PBS. For sperm permeabilisation, the smears were incubated with $0.1 \%$ Triton $\mathrm{X}-100$ in $0.1 \%$ sodium citrate, $\mathrm{pH}=6.0$, for 15 minutes at RT. Then, $50 \mu \mathrm{L}$ of the TdT-labelled nucleotide mixture (50 $\mu \mathrm{L}$ of enzyme and $450 \mu \mathrm{L}$ of label solutions) was added to each slide and incubated in a humidified chamber at $37^{\circ} \mathrm{C}$ in the dark overnight. Then, the slides were rinsed twice with PBS buffer and $25 \mu \mathrm{L}$ of $5 \mu \mathrm{g} / \mathrm{mL} 4$, and 6-diamidino-2-phenylindole (DAPI) stain was added to each slide as a counter stain. For evaluation, a total of 200 SPZ were analysed on each slide by distinguishing SPZ stained green (TUNEL-positive with fragmented DNA) from those stained blue (TUNEL-negative with intact DNA). A fluorescence microscope (Olympus BX61, Japan), DAPI and FITEC filters, and Meta Systems 
Isis software were used for fluorochrome evaluation via a combination of exciter dichromic barrier filter of BP (band pass) (436/10:FT, 580:LP 470). A negative control was performed for each sample using fluorescent isothiocyanate-labelled dUTP without enzyme.

\section{Sperm Protamine Extraction}

As previously explained, sperm nuclear protamines were extracted from all the studied semen samples (19). The sperm pellets with determined sperm concentration were removed from the storage at $-20^{\circ} \mathrm{C}$ and used for protamine extraction. The pellets were washed in $1 \mathrm{ml}$ of washing buffer I containing $1 \mathrm{mM}$ ( $\mathrm{mmol} / \mathrm{L})$ of phenylmethylsulfonyl fluoride in distilled water (PMSF) and centrifuged at $250 \times \mathrm{g}$ for 5 minutes at RT. Then, the pellet was re-suspended in $100 \mu \mathrm{L}$ of wash buffer 2 containing $20 \mathrm{mM}$ EDTA (ethylenediaminetetraacetic acid) and PMSF (1 mmol, $\mathrm{pH}=8.0)$ and vortexed for 15 seconds. Then, $100 \mu \mathrm{L}$ of decondensation buffer 1 (6 M guanidine hydrochloride and $575 \mathrm{mM}$ dithiothreitol) was added and vortexed for 15 seconds followed by the addition of $200 \mu \mathrm{L}$ of decondensation buffer $2(522 \mathrm{mM}$ sodium iodoacetate) and vortexing for 30 seconds.

The component was then incubated in the dark at RT for 30 minutes and $1 \mathrm{~mL}$ of cold absolute ethanol was added; the sample was then mixed and incubated at $-20^{\circ} \mathrm{C}$ for 1 minute. The mixture was centrifuged at $1000 \times g$ for 10 minutes at $4^{\circ} \mathrm{C}$ and the supernatant discarded (this step was repeated once). The pellet was re-suspended in $80 \mu \mathrm{L}$ of denaturing solution $(0.5 \mathrm{M} \mathrm{HCl})$, mixed, and incubated for 15 minutes at $37^{\circ} \mathrm{C}$. The sample was then centrifuged at $1000 \times g$ for 10 minutes at $4^{\circ} \mathrm{C}$. Next, the supernatant was transferred to another tube containing $200 \mu \mathrm{l}$ of precipitating solution (100\% trichloroacetic acid). The mixture was incubated on ice for 3 minutes and centrifuged at $1000 \times \mathrm{g}$ for 10 minutes at $4^{\circ} \mathrm{C}$. The supernatant was removed carefully. Then, the precipitate was washed in $1 \mathrm{~mL}$ of wash buffer 3 ( $1 \% \beta$-mercaptoethanol in $100 \%$ acetone) and vortexed for 15 seconds. The preparation was centrifuged at $1000 \times g$ for 8 minutes at $4^{\circ} \mathrm{C}$ and the supernatant was removed. The final pellet was dried at $4^{\circ} \mathrm{C}$ overnight and stored at $-80^{\circ} \mathrm{C}$ until further analysis.

\section{Preparation of the Human Protamine Standard}

A human protamine standard was prepared according to what has been previously described (19). Sperm samples of 20 fertile donors were pooled in order to extract and estimate sperm protamines. The semen samples were centrifuged at $250 \times \mathrm{g}$ for 10 minutes at RT to remove the seminal plasma, then they were washed with PBS and centrifuged at $250 \times \mathrm{g}$ for 10 minutes at RT. The supernatant was discarded. The pellet of each sample was re-suspended in $.5 \mathrm{ml}$ of the denaturing solution $(0.5 \mathrm{M}$ $\mathrm{HCl})$ and incubated at $37^{\circ} \mathrm{C}$ for 15 minutes. The samples were then centrifuged at $250 \times \mathrm{g}$ for 5 minutes at RT and the supernatant was also removed. The pellets were washed with $0.25 \mathrm{ml}$ of washing buffer 2 (20 mM EDTA \& $1 \mathrm{mM}$ PMSF in $0.1 \mathrm{M}$ Tris, $\mathrm{pH}=8.0$ ) and centrifuged at $250 \times$ $\mathrm{g}$ for 5 minutes at RT and the supernatant was discarded as well. Nuclear proteins were extracted as described above. The final protein concentration was determined using the RCDC (educing agent compatible-detergent compatible) protein assay kit (BioRad Laboratories, Hercules, CA, USA) and an Ultrospec 2100 pro UV/ Visible spectrophotometer (Amersham Biosciences Inc., Cambridge, UK). A regression curve was obtained from the four different concentrations of protamine standard $(1.5,1,0.5$, and $0.25 \mu \mathrm{g} / \mu \mathrm{L})$ included in each gel; the intensity of their bands were also obtained in order to calculate the amount of P1 and P2 in each sample. The value of the regression curve $\left(R^{2}\right)$ was $\geq 0.98$ for each gel.

\section{Extraction of Protamine from Control Samples}

Semen samples were pooled from 10 fertile men and treated as in the standard preparation.

In total, according to the procedure explained above, aliquots of $40 \times 10^{6}$ sperm were prepared and stored at $-80^{\circ} \mathrm{C}$. One aliquot was extracted in tandem with test samples for every run. The sperm protamine extraction protocol, as described above, was followed.

\section{Quantification of P1 and P2 With Acetic AU-PAGE and WB}

Protamine extracts were analysed, as previously described, using the AU-PAGE method (19). Extracted nucleoproteins were dissolved in $80 \mathrm{~mL}$ of loading buffer $(0.375 \mathrm{M}$ potassium acetate, $\mathrm{pH}=4.0,15 \%$ sucrose, and $0.05 \%$ methyl green). The stacking gel was prepared with $7.5 \%(\mathrm{w} / \mathrm{v})$ acrylamide, $.8 \%(\mathrm{w} / \mathrm{v})$ $\mathrm{N}, \mathrm{N}^{\prime}$-methylenebisacrylamide solution, and $0.375 \mathrm{M}$ potassium acetate $(\mathrm{pH}=4.0)$. The separating gel was prepared with $20 \%(\mathrm{w} / \mathrm{v})$ acrylamide and $0.8 \%(\mathrm{w} / \mathrm{v})$ $\mathrm{N}, \mathrm{N}^{\prime}$-methylenebisacrylamide solution. For both gels, $2.5 \mathrm{M}$ urea and $43 \%$ acetic acid were used. In addition, for polymerization, $1.6 \%(\mathrm{w} / \mathrm{v})$ ammonium persulfate was used for both gels and 0.5 and $2 \%(\mathrm{w} / \mathrm{v}) \mathrm{N}, \mathrm{N}, \mathrm{N}^{\prime}, \mathrm{N}^{\prime}-$ tetramethylendiamine for resolving and stacking the gels, respectively. Then, the gels were pre-run at $200 \mathrm{~V}$ and 40 $\mathrm{mA}$ for 1.5 hours. Nucleoprotein samples were loaded on to the gel and run at $200 \mathrm{~V}$ and $80 \mathrm{~mA}$ for 5-6 hours.

The horseradish peroxidase-conjugated goat antimouse IgG (Dianova, Germany) antibody was diluted 1:10000 ratio and incubated for 1 hour at RT. Protamines were detected using the lumi-light chemiluminescence kit (Roche, Germany). Negative immunoblot controls were performed, as above, without the primary antibody. Protamine bands were visualized using the enhance chemiluminescence system (Bio-Rad, Germany). The intensity of the bands corresponding to P1 and P2 were quantified. The P1 and P2 concentrations were calculated from the standard curve generated from the human 
protamine standard as described above. The $\mathrm{P} 1 / \mathrm{P} 2$ ratio of each sample was calculated and the mean values were reported as well. All the samples were tested in duplicate.

Statistical Analysis

Analysis was performed at the Institute of Medical Biometry and Medical Information, University of the Saarland, using SPSS (statistical package for the social sciences) software, version 23. The obtained data were provided as the median \pm standard deviation and the different correlations were described according to the correlation coefficient " $r$ " Spearman. Comparison of the medians was determined using the independent sample $t$ test (Mann-Whitney U test).

\section{Results}

Following quantification of protamine $\mathrm{P} 1$ and $\mathrm{P} 2$, the P1/ $\mathrm{P} 2$ ratio was determined and patients were divided into 3 groups according to P1/P2 values: $\mathrm{G} 1(\mathrm{n}=11)$, low $\mathrm{P} 1 / \mathrm{P} 2$

Table 1. Median, Standard Deviation of Semen Parameters, DFI, CMA3 Positive and Protamine's Measurement by All Investigated Samples $(\mathrm{N}=272)$

\begin{tabular}{ll}
\hline Parameters & Median \pm SD \\
\hline Age $(\mathrm{y})$ & $33.53 \pm 7.36$ \\
Concentration $\left(\times 10^{6} / \mathrm{mL}\right)$ & $64.81 \pm 39.66$ \\
Progressive motility $(\%)$ & $35.90 \pm 18.64$ \\
Normal morphology $(\%)$ & $29.65 \pm 23.46$ \\
DFI (\%) & $14.60 \pm 8.58$ \\
CMA positive $(\%)$ & $34.30 \pm 15.97$ \\
Protamine $1\left(\mathrm{ng} / 10^{6} \mathrm{SPZ}\right)$ & $432.35 \pm 124.14$ \\
Protamine 2 $\left(\mathrm{ng} / 10^{6} \mathrm{SPZ}\right)$ & $397.85 \pm 125.19$ \\
P1/P2 ratio & $0.83 \pm .49$
\end{tabular}

Abbreviations: SPZ, spermatozoa; SD, standard deviation ratio $(<0.80)$; $\mathrm{G} 2(\mathrm{n}=98)$, normal $\mathrm{P} 1 / \mathrm{P} 2$ ratio $(0.8-1.20)$; and $\mathrm{G} 3(\mathrm{n}=61)$, high $\mathrm{P} 1 / \mathrm{P} 2$ ratio $(>1.20)$.

The means for age, sperm concentration, progressive motility, and normal morphology of all the investigated patients were $33.53 \pm 7.36$ years, $64.81 \pm 39.66 \times 10^{6} /$ $\mathrm{mL}, 35.90 \pm 18.64 \%$, and $29.65 \pm 23.46 \%$, respectively. In addition, the medians of the DFI measured by TUNEL staining and chromatin condensation (protamination) measured by $\mathrm{CMA}_{3}$ staining were $14.60 \pm 8.58 \%$ and $34.30 \pm 15.97 \%$, respectively. Besides, concentrations of protamine P1 and P2 were 432.35 \pm 124.14 and $397.85 \pm 125.19 \mathrm{ng} / 10^{6} \mathrm{SPZ}$, respectively, and the P1/P2 ratio was $0.83 \pm 0.49$ (Table 1 ).

Patients (G1) With Low P1/P2 Ratio $(<0.80)$

A positive correlation was observed between the $\mathrm{P} 1 / \mathrm{P} 2$ ratio and the age of males $(r=0.354, P=.001)$. The $\mathrm{P} 1 / \mathrm{P} 2$ ratio showed highly significant negative correlations with sperm concentration $(\mathrm{r}=0.465, P=0.001)$, progressive motility ( $\mathrm{r}=0.381 ; P=0.001)$, and normal morphology $(\mathrm{r}=0.765, P=0.001)$ (Table 2).

The DFI demonstrated a significantly positive correlation with the $\mathrm{P} 1 / \mathrm{P} 2$ ratio $(\mathrm{r}=0.652, P=0.001)$ and chromatin condensation was found to have a significantly negative correlation with the $\mathrm{P} 1 / \mathrm{P} 2$ ratio $(\mathrm{r}=0.623$, $P=0.001$ ) (Table 3 ). The $\mathrm{P} 1$ and $\mathrm{P} 2$ values were positively associated $(\mathrm{r}=0.746, P=0.001)$ (Table 3$)$, but neither of them was correlated with $\mathrm{P} 1 / \mathrm{P} 2$ ratio.

Patients (G2) With Normal P1/P2 Ratio (0.80 $\leq$ ratio $\leq$ 1.20)

In contrast to G1, participants' age did not correlate with the studied parameters (Table 4). However, sperm concentration was positively correlated with $\mathrm{P} 1(\mathrm{r}=0.257$,

Table 2. Correlations Between Different Parameters Measured by Patients With Low P1/P2 Ratio (Ratio <0.8)

\begin{tabular}{|c|c|c|c|c|c|}
\hline Parameters & & Age (y) & Concentration $\left(10^{6} \mathrm{spz} / \mathrm{mL}\right)$ & Progressive Motility (\%) & Normal Morphology (\%) \\
\hline \multirow{2}{*}{ Age (y) } & $r$ & 1.000 & $-0.288^{* *}$ & $-0.196^{*}$ & $-0.407^{* *}$ \\
\hline & $P$ & - & 0.002 & 0.038 & 0.001 \\
\hline \multirow{2}{*}{$\begin{array}{l}\text { Concentration } \\
\left(10^{6} \mathrm{spz} / \mathrm{mL}\right)\end{array}$} & $r$ & $-0.288^{* *}$ & 1.000 & $0.196^{*}$ & $0.512^{* *}$ \\
\hline & $P$ & 0.002 & - & 0.038 & 0.001 \\
\hline \multirow{2}{*}{ Progressive motility (\%) } & $r$ & $-0.196^{*}$ & $0.196^{*}$ & 1.000 & $0.411^{* *}$ \\
\hline & $P$ & 0.038 & 0.038 & - & 0.001 \\
\hline \multirow{2}{*}{ Normal morphology (\%) } & $r$ & $-0.407^{* *}$ & $0.512^{* *}$ & $0.411^{* *}$ & 1.000 \\
\hline & $P$ & 0.001 & 0.001 & 0.001 & - \\
\hline \multirow{2}{*}{ DFI (\%) } & $r$ & $0.225^{*}$ & -0.156 & $-0.407^{* *}$ & $-0.306^{* *}$ \\
\hline & $P$ & 0.017 & 0.098 & 0.001 & 0.001 \\
\hline \multirow{2}{*}{ CMA3 positive (\%) } & $r$ & $-0.336^{* *}$ & $0.273^{* *}$ & $0.345^{* *}$ & $0.675^{* *}$ \\
\hline & $P$ & 0.001 & 0.001 & 0.001 & 0.001 \\
\hline \multirow{2}{*}{$\mathrm{P} 1$ (ng/10 $\mathrm{spz}$ ) } & $r$ & -0.054 & 0.136 & -0.086 & -0.065 \\
\hline & $P$ & 0.567 & 0.152 & 0.365 & 0.496 \\
\hline \multirow{2}{*}{$\mathrm{P} 2$ (ng/10 $\mathrm{spz}$ ) } & $r$ & -0.070 & 0.069 & -0.004 & -0.050 \\
\hline & $P$ & 0.463 & 0.468 & 0.966 & 0.602 \\
\hline \multirow{2}{*}{$\mathrm{P} 1 / \mathrm{P} 2$ ratio } & $r$ & $0.354^{* *}$ & $-0.465^{* *}$ & $-0.381^{* *}$ & $-0.765^{* *}$ \\
\hline & $P$ & 0.001 & 0.001 & 0.001 & 0.001 \\
\hline
\end{tabular}

Abbreviations: SPZ, spermatozoa.

${ }^{* *}$ Correlation is significant at the 0.01 level $(P<0.01)$; ${ }^{*}$ Correlation is significant at the 0.05 level $(P<0.05)$. 
Table 3. Correlations Between Different Parameters Measured by Patients With Low P1/P2 Ratio (Ratio <0.8)

\begin{tabular}{|c|c|c|c|c|c|c|}
\hline Parameters & & DFI (\%) & CMA3 Positive (\%) & P1 (ng/10 spz) & $\mathrm{P} 2$ (ng/10 $\mathrm{spz}$ ) & (P1/P2) Ratio \\
\hline \multirow{2}{*}{ DFI (\%) } & $r$ & 1.000 & $-0.371^{* *}$ & -0.028 & -0.058 & $0.652^{* *}$ \\
\hline & $P$ & - & 0.001 & 0.772 & 0.544 & 0.001 \\
\hline \multirow{2}{*}{ CMA3 positive (\%) } & $r$ & $-0.371^{* *}$ & 1.000 & -0.117 & 0.051 & $-0.623^{* *}$ \\
\hline & $P$ & 0.001 & - & 0.216 & 0.594 & 0.001 \\
\hline \multirow{2}{*}{$\mathrm{P} 1$ (ng/10 $\mathrm{spz})$} & $r$ & -0.028 & -0.117 & 1.000 & $0.746^{* *}$ & 0.062 \\
\hline & $P$ & 0.772 & 0.216 & - & 0.001 & 0.514 \\
\hline \multirow{2}{*}{$\mathrm{P} 2$ (ng/10 $\mathrm{spz}$ ) } & $r$ & -0.058 & 0.051 & $0.746^{* *}$ & 1.000 & 0.068 \\
\hline & $P$ & 0.544 & 0.594 & 0.001 & - & 0.477 \\
\hline \multirow{2}{*}{$\mathrm{P} 1 / \mathrm{P} 2$ ratio } & $r$ & $0.652^{* *}$ & $-0.623^{* *}$ & 0.062 & 0.068 & 1.000 \\
\hline & $P$ & 0.001 & 0.001 & 0.514 & 0.477 & - \\
\hline
\end{tabular}

Abbreviations: SPZ, spermatozoa.

${ }^{* *}$ Correlation is significant at the 0.01 level $(P<0.01) ; *$ Correlation is significant at the 0.05 level $(P<0.05)$.

Table 4. Correlations Between Different Parameters Measured by Patients With Normal P1/P2 Ratio $(0.8 \leq$ Ratio $\leq 1.2)$

\begin{tabular}{|c|c|c|c|c|c|}
\hline Parameters & & Age (y) & Concentration $\left(10^{6} \mathrm{spz} / \mathrm{mL}\right)$ & Progressive Motility (\%) & Normal Morphology (\%) \\
\hline \multirow{2}{*}{ Age (y) } & $r$ & 1.000 & -0.007 & -0.037 & -0.096 \\
\hline & $P$ & & 0.947 & 0.720 & 0.348 \\
\hline \multirow{2}{*}{$\begin{array}{l}\text { Concentration } \\
\left(10^{6} \mathrm{spz} / \mathrm{mL}\right)\end{array}$} & $r$ & -0.007 & 1.000 & $0.577^{* *}$ & 0.003 \\
\hline & $P$ & 0.947 & & 0.001 & 0.980 \\
\hline \multirow{2}{*}{ Progressive motility (\%) } & $r$ & -0.037 & $0.577^{* *}$ & 1.000 & -0.039 \\
\hline & $P$ & 0.720 & 0.001 & - & 0.702 \\
\hline \multirow{2}{*}{ Normal morphology (\%) } & $r$ & -0.096 & 0.003 & -0.039 & 10.000 \\
\hline & $P$ & 0.348 & 0.980 & 0.702 & - \\
\hline \multirow{2}{*}{ DFI (\%) } & $r$ & 0.102 & $-0.203^{*}$ & $-0.304 * *$ & -0.029 \\
\hline & $P$ & 0.315 & 0.044 & 0.002 & 0.780 \\
\hline \multirow{2}{*}{ CMA3 positive (\%) } & $r$ & -0.028 & $-0.410 * *$ & $-0.238^{*}$ & $-0.217^{*}$ \\
\hline & $P$ & 0.787 & 0.001 & 0.018 & 0.032 \\
\hline \multirow{2}{*}{$\mathrm{P} 1$ (ng/10 $\mathrm{spz})$} & $r$ & 0.053 & $0.257^{*}$ & $0.352^{* *}$ & $-0.206^{*}$ \\
\hline & $P$ & 0.604 & 0.011 & 0.001 & 0.041 \\
\hline \multirow{2}{*}{$\mathrm{P} 2$ (ng/10 $\mathrm{spz}$ ) } & $r$ & 0.061 & $0.277^{* *}$ & $0.380 * *$ & $-0.208^{*}$ \\
\hline & $P$ & 0.553 & 0.006 & 0.001 & 0.040 \\
\hline \multirow{2}{*}{$\mathrm{P} 1 / \mathrm{P} 2$ ratio } & $r$ & 0.012 & -0.143 & -0.091 & 0.034 \\
\hline & $P$ & 0.906 & 0.160 & 0.374 & 0.738 \\
\hline
\end{tabular}

Abbreviations: SPZ, spermatozoa.

${ }^{* *}$ Correlation is significant at the 0.01 level $(P<0.01) ; *$ Correlation is significant at the 0.05 level $(P<0.05)$.

$P=0.011)$ and $\mathrm{P} 2 \quad(\mathrm{r}=0.277, P=0.006)$. The mean percentage of morphologically normal SPZ demonstrated a significant negative correlation with P1 $(r=-0.206$, $P=0.041)$ and $\mathrm{P} 2(\mathrm{r}=-0.208, P=0.040)$ (Table 4$)$. The DFI showed no correlation with the $\mathrm{P} 1 / \mathrm{P} 2$ ratio. Similarly, no association was observed between the $\mathrm{P} 1 / \mathrm{P} 2$ ratio and chromatin condensation $(r=0.333, P=0.001)$ (Table 5).

Patients (G3) With High P1/P2 Ratio (>1.20)

In G3, there was no correlation between males' age and the investigated sperm parameters in the present study (Tables 6 and 7). The P1 demonstrated a significantly positive correlation with P2 $(r=0.785, P=0.001)$ (Table 7) while $P 1$ showed a significantly negative correlation $(r=-0.299$, $P=0.027)$ with the mean percentage of morphologically normal SPZ (Table 6). The P1/P2 ratio in G3 was only significantly and negatively correlated with P2 $(r=-0.372$,
$P=0.003)$ (Table 7).

Comparison of Studied Parameters Between Ratio Groups (Low, Normal, and High)

Table 8 illustrates the different studied parameters (as the median \pm standard deviation) compared between all the 3 groups. The age and DFI were significantly higher in G3 compared with G1 and G2 $(P=0.016$ and $P=0.001$, respectively). In addition, the progressive motility and $\mathrm{P} 2$ values were significantly higher in G2 $(P=0.001)$. Besides, the mean percentage of morphologically normal SPZ and $\mathrm{CMA}_{3}$-positive values were significantly higher in G1 $(P=0.001)$ while the $\mathrm{P} 1$ value was significantly lower in this group compared with the other groups $(P=0.001)$.

Discussion

Protamine ratio $(\mathrm{P} 1 / \mathrm{P} 2)$ at the level of $0.8-1.2$ in semen 
Table 5. Correlations Between Different Parameters Measured by Patients With Normal P1/P2 Ratio (0.8 $\leq$ Ratio $\leq 1.2)$

\begin{tabular}{|c|c|c|c|c|c|c|}
\hline Parameters & & DFI (\%) & CMA3 Positive (\%) & P1 (ng/10 $\mathrm{spz})$ & $\mathrm{P} 2$ (ng/10 $\mathrm{spz})$ & (P1/P2) Ratio \\
\hline \multirow{2}{*}{ DFI (\%) } & $r$ & 1.000 & 0.143 & $-0.207^{*}$ & -0.198 & 0.028 \\
\hline & $P$ & - & 0.161 & 0.041 & 0.051 & 0.782 \\
\hline \multirow{2}{*}{ CMA3 positive (\%) } & $r$ & 0.143 & 1.000 & -0.016 & -0.064 & $0.333^{* *}$ \\
\hline & $P$ & 0.161 & - & 0.873 & 0.534 & 0.001 \\
\hline \multirow{2}{*}{$\mathrm{P} 1$ (ng/10 $\mathrm{spz}$ ) } & $r$ & $-0.207^{*}$ & -0.016 & 1.000 & $0.969 * *$ & 0.136 \\
\hline & $P$ & 0.041 & 0.873 & - & 0.001 & 0.181 \\
\hline \multirow{2}{*}{$\mathrm{P} 2$ (ng/106 spz) } & $r$ & -0.198 & -0.064 & $0.969 * *$ & 1.000 & -0.054 \\
\hline & $P$ & 0.051 & 0.534 & 0.001 & - & 0.597 \\
\hline \multirow{2}{*}{ P1/P2 ratio } & $r$ & 0.028 & $0.333 * *$ & 0.136 & -0.054 & 1.000 \\
\hline & $P$ & 0.782 & 0.001 & 0.181 & 0.597 & - \\
\hline
\end{tabular}

Abbreviations: SPZ, spermatozoa.

${ }^{* *}$ Correlation is significant at the 0.01 level $(P<0.01) ;{ }^{*}$ Correlation is significant at the 0.05 level $(P<0.05)$.

Table 6. Correlations Between Different Parameters Measured by Patients With High P1/P2 Ratio (Ratio >1.2)

\begin{tabular}{|c|c|c|c|c|c|}
\hline Parameters & & Age (y) & Concentration $\left(10^{6} \mathrm{spz} / \mathrm{mL}\right)$ & Progressive Motility (\%) & Normal Morphology (\%) \\
\hline \multirow{2}{*}{ Age (y) } & $r$ & 1.000 & 0.055 & -0.211 & -0.160 \\
\hline & $P$ & - & 0.678 & 0.103 & 0.217 \\
\hline \multirow{2}{*}{$\begin{array}{l}\text { Concentration } \\
\left(10^{6} \mathrm{spz} / \mathrm{mL}\right)\end{array}$} & $r$ & 0.055 & 1.000 & $0.256^{*}$ & -0.017 \\
\hline & $P$ & 0.678 & - & 0.048 & 0.899 \\
\hline \multirow{2}{*}{ Progressive motility (\%) } & $r$ & -0.211 & $0.256^{*}$ & 1.000 & -0.221 \\
\hline & $P$ & 0.103 & 0.048 & - & 0.087 \\
\hline \multirow{2}{*}{ Normal morphology (\%) } & $r$ & -0.160 & -0.017 & -0.221 & 1000 \\
\hline & $P$ & 0.217 & 0.899 & 0.087 & - \\
\hline \multirow{2}{*}{ DFI (\%) } & $r$ & 0.103 & -0.165 & $-0.454 * *$ & $0.441^{* *}$ \\
\hline & $P$ & 0.429 & 0.208 & 0.001 & 0.001 \\
\hline \multirow{2}{*}{ CMA3 positive (\%) } & $r$ & -0.168 & $-0.628 * *$ & -0.178 & 0.123 \\
\hline & $P$ & 0.195 & 0.001 & 0.170 & 0.345 \\
\hline \multirow{2}{*}{$\mathrm{P} 1$ (ng/106 spz) } & $r$ & 0.166 & 0.037 & 0.173 & $-0.283^{*}$ \\
\hline & $P$ & 0.202 & 0.780 & 0.183 & 0.027 \\
\hline \multirow{2}{*}{$\mathrm{P} 2$ (ng/10 $\mathrm{spz}$ ) } & $r$ & 0.105 & -0.021 & 0.131 & -0.107 \\
\hline & $P$ & 0.419 & 0.873 & 0.313 & 0.412 \\
\hline \multirow{2}{*}{$\mathrm{P} 1 / \mathrm{P} 2$ ratio } & $r$ & 0.131 & 0.185 & -0.177 & -0.216 \\
\hline & $P$ & 0.315 & 0.158 & 0.171 & 0.095 \\
\hline
\end{tabular}

Abbreviations: SPZ, spermatozoa.

${ }^{* *}$ Correlation is significant at the 0.01 level $(P<0.01) ; *$ Correlation is significant at the 0.05 level $(P<0.05)$.

Table 7. Correlations Between Different Parameters Measured by Patients With Normal P1/P2 Ratio (0.8 $\leq$ Ratio $\leq 1.2)$

\begin{tabular}{|c|c|c|c|c|c|c|}
\hline Parameters & & DFI (\%) & CMA3 Positive (\%) & P1 (ng/106 spz) & $\mathrm{P} 2$ (ng/10 $\mathrm{spz}$ ) & (P1/P2) Ratio \\
\hline \multirow{2}{*}{ DFI (\%) } & $r$ & 1.000 & $0.299 *$ & -0.078 & -0.040 & 0.179 \\
\hline & $P$ & 0. & 0.019 & 0.552 & 0.757 & 0.167 \\
\hline \multirow{2}{*}{ CMA3 positive (\%) } & $r$ & $0.299 *$ & 1.000 & -0.082 & -0.028 & -0.138 \\
\hline & $P$ & 0.019 & - & 0.529 & 0.831 & 0.288 \\
\hline \multirow{2}{*}{$\mathrm{P} 1$ (ng/10 $\mathrm{spz}$ ) } & $r$ & -0.078 & -0.082 & 1.000 & $0.785^{* *}$ & 0.095 \\
\hline & $P$ & 0.552 & 0.529 & - & 0.001 & 0.181 \\
\hline \multirow{2}{*}{$\mathrm{P} 2$ (ng/10 $10^{6} \mathrm{sp}$ ) } & $r$ & -0.040 & -0.028 & $0.785^{* *}$ & 1.000 & $-0.372^{* *}$ \\
\hline & $P$ & 0.757 & 0.831 & 0.001 & - & 0.003 \\
\hline \multirow{2}{*}{$\mathrm{P} 1 / \mathrm{P} 2$ ratio } & $r$ & 0.179 & -0.138 & 0.095 & $-0.372 * *$ & 1.000 \\
\hline & $P$ & 0.167 & 0.288 & 0.181 & 0.003 & - \\
\hline
\end{tabular}

Abbreviations: SPZ, spermatozoa.

${ }^{* *}$ Correlation is significant at the 0.01 level $(P<0.01) ; *$ Correlation is significant at the 0.05 level $(P<0.05)$. 
Table 8. Comparison of Sperm Parameters Between the 3 Groups of Protamine Ratio P1/P2

\begin{tabular}{|c|c|c|c|c|}
\hline Parameters & Age (y) & Concentration $\left(10^{6} \mathrm{spz} / \mathrm{mL}\right)$ & Progressive Motility (\%) & Normal Morphology (\%) \\
\hline \multirow{2}{*}{ Age (y) } & $32.10 \pm 7.65$ & $34.09 \pm 6.84$ & $35.26 \pm 7.23$ & $0.016^{*}$ \\
\hline & $66.67 \pm 33.50$ & $68.23 \pm 45.40$ & $55.70 \pm 39.67$ & 0.126 \\
\hline \multirow{2}{*}{$\begin{array}{l}\text { Concentration } \\
\left(10^{6} \mathrm{spz} / \mathrm{mL}\right)\end{array}$} & $31.18 \pm 15.17$ & $43.19 \pm 19.88$ & $32.93 \pm 19.06$ & $0.001 * *$ \\
\hline & $36.02 \pm 17.37$ & $21.74 \pm 23.30$ & $30.57 \pm 29.43$ & $0.001 * *$ \\
\hline \multirow{2}{*}{ Progressive motility (\%) } & $12.02 \pm 8.01$ & $14.60 \pm 7.12$ & $19.44 \pm 9.71$ & $0.001 * *$ \\
\hline & $39.84 \pm 14.09$ & $29.26 \pm 14.36$ & $32.13 \pm 18.60$ & $0.001 * *$ \\
\hline \multirow{2}{*}{ Normal morphology (\%) } & $392.03 \pm 115.94$ & $460.84 \pm 123.73$ & $461.27 \pm 120.53$ & $0.001 * *$ \\
\hline & $372.69 \pm 116.91$ & $455.09 \pm 123.23$ & $352.52 \pm 109.96$ & $0.001 * *$ \\
\hline \multirow{2}{*}{ DFI (\%) } & $0.39 \pm 0.25$ & $1.01 \pm .05$ & $1.3513 \pm 0.24$ & $0.001 * *$ \\
\hline & 0.429 & 0.208 & 0.001 & 0.001 \\
\hline \multirow{2}{*}{ CMA3 positive (\%) } & -0.168 & $-0.628 * *$ & -0.178 & 0.123 \\
\hline & 0.195 & 0.001 & 0.170 & 0.345 \\
\hline \multirow{2}{*}{$\mathrm{P} 1$ (ng/10 $\mathrm{spz})$} & 0.166 & 0.037 & 0.173 & $-0.283^{*}$ \\
\hline & 0.202 & 0.780 & 0.183 & 0.027 \\
\hline \multirow{2}{*}{$\mathrm{P} 2$ (ng/106 spz) } & 0.105 & -0.021 & 0.131 & -0.107 \\
\hline & 0.419 & 0.873 & 0.313 & 0.412 \\
\hline \multirow{2}{*}{ P1/P2 ratio } & 0.131 & 0.185 & -0.177 & -0.216 \\
\hline & 0.315 & 0.158 & 0.171 & 0.095 \\
\hline
\end{tabular}

Abbreviations: SPZ, spermatozoa.

${ }^{* *}$ Correlation is significant at the 0.01 level $(P<0.01) ;{ }^{*}$ Correlation is significant at the 0.05 level $(P<0.05)$.

has been associated with male infertility (12). This has generated significant interest in determining whether the $\mathrm{P} 1 / \mathrm{P} 2$ ratio can be a useful biomarker for sperm of people undergoing IVF or ICSI therapy, especially given that classical semen analysis does not provide sufficient information with respect to the quality and function of the sperm.

In the present study, the $\mathrm{P} 1$ and $\mathrm{P} 2$ values in the first group $(\mathrm{P} 1 / \mathrm{P} 2$ ratio $<0.8)$ showed no correlation with the age of the males, standard sperm parameters, DFI, chromatin condensation $\left(\mathrm{CMA}_{3}\right)$, and the $\mathrm{P} 1 / \mathrm{P} 2$ ratio' although higher positive correlations $(r=0.746, P=0.001)$ were confirmed between the P1 and P2 concentrations.

In $\mathrm{G} 2$, the protamines $\mathrm{P} 1$ and $\mathrm{P} 2$, in addition to their high positive correlation $(r=0.969, P=0.001)$, demonstrated similar correlations with other parameters in particular, sperm concentration and P1 $(r=0.257, P=0.011)$ and P2 $(r=0.277, P=0.006)$ values. Progressive motility had a significantly positive correlation with $\mathrm{P} 1 \quad(\mathrm{r}=0.352$, $P=0.001)$ and $\mathrm{P} 2(\mathrm{r}=0.380, P=0.001)$ values. The mean percentage of morphologically normal SPZ demonstrated a significantly negative correlation with P1 $(r=-0.206$, $P=0.041)$ and $\mathrm{P} 2(\mathrm{r}=-0.208, P=0.040)$ values.

In $\mathrm{G} 3$, the $\mathrm{P} 1 / \mathrm{P} 2$ ratio demonstrated only one significantly negative correlation with P2 $(r=-0.372$, $P=0.003$ ). The $\mathrm{P} 1$ concentration was found to have a significantly positive association with $\mathrm{P} 2$ value $(\mathrm{r}=0.785$, $P=0.001)$ and a significant negative correlation $(\mathrm{r}=-0.283$, $P=0.027$ ) was also observed between the mean percentage of morphologically normal SPZ and P1 concentration.

It seems that the alterations in $\mathrm{P} 1 / \mathrm{P} 2$ ratio affected the quality and function of SPZ. These results are in agreement with findings of previous studies $(21,22)$ which showed that sperm concentration, motility, viability, and mean percentage of morphologically normal SPZ were decreased in patients with an abnormal $\mathrm{P} 1 / \mathrm{P} 2$ ratio. These results are also in accordance with the results obtained by other studies demonstrating that protamine deficiency resulted in a severe disruption of spermatogenesis affecting male infertility $(23,24)$. In addition, the protamine expression disorder resulted in a decrease in number, motility, and morphology of SPZ (25).

Similarly, Iranpour (25) found that patients presenting an abnormal P1/P2 ratio showed less sperm with normal heads and more tapered heads in comparison with patients with a normal protamine ratio. However, the differences were not significant in this study. This is in line with the result of the present study, which demonstrated a negative correlation with the mean percentage of morphologically normal SPZ at the level of the 3 groups for P1, P2, and P1/ $\mathrm{P} 2$ ratio. Moreover, the results of the current study are in conformity with the findings of a study by Aoki et al (12), who found that alterations in $\mathrm{P} 1 / \mathrm{P} 2$ ratio were associated with a reduction of progressive motility and morphology of sperm.

An increase in the expression of P2 precursors discovered among infertile individuals explained their low levels of $\mathrm{P} 2$, indicating that disorders might occur during the processing of $\mathrm{P} 2$ (27). The pre-P1/P2 ratio can therefore influence the $\mathrm{P} 1 / \mathrm{P} 2$ ratio (28) leading to a defective compaction of sperm DNA and changing the sperm quality. In addition, alteration of the P1/P2 ratio can occur as a consequence of the replacement of histones during faulty spermiogenesis. Indeed, increased histone levels have been reported in the semen of infertile men compared with fertile controls $(29,30)$. 
Overall, alterations in the $\mathrm{P} 1 / \mathrm{P} 2$ ratio were appeared to play a key role in male infertility. However, the exact mechanisms by which this may occur can differ between individuals, and the underlying mechanisms have not yet been elucidated. Moreover, protamines were found to play a critical role in sperm chromatin condensation and the protection of paternal genomic DNA from alterations $(21,31,32)$. It has also been proposed that a deficiency in protamine may lead to the accumulation of lesions at the level of spermatic DNA $(33,34)$, morphological abnormalities, the triggering of apoptotic pathways, mitochondrial inactivation, and consequently a decrease in sperm motility (35).

Thus, it would be useful to determine with certainty if a particular alteration of DNA is linked to protamination defects. Until recently, the most commonly used method to analyse the protamine deficiencies has been the $\mathrm{CMA}_{3}$ method and, according to some studies, measurement of the P1/P2 ratio has been shown to be closely related to sperm DNA $(15-17,21,36,37)$. Furthermore, in the present study, the association between protamine deficiencies and sperm DNA lesions was systematically analysed. It was found that in G1, the $\mathrm{CMA}_{3}$ and DFI were negatively correlated $(\mathrm{r}=-0.371, P=0.001)$. The P1/ P2 ratio demonstrated a positive correlation with DFI $(\mathrm{r}=0.652, P=0.001)$ but a negative correlation with $\mathrm{CMA}_{3}$ $(\mathrm{r}=-0.623, P=0.001)$. In $\mathrm{G} 2$, the $\mathrm{P} 1 / \mathrm{P} 2$ ratio showed a positive association $(\mathrm{r}=0.333, P=0.001)$ with $\mathrm{CMA}_{3}$ while $\mathrm{P} 1$ had a negative correlation $(\mathrm{r}=-0.207, P=0.041)$ with DFI. In contrast to G1, the DFI and $\mathrm{CMA}_{3}$ were positively correlated $(\mathrm{r}=0.299, P=0.019)$ in $\mathrm{G} 3$.

It has been shown that DFI was significantly higher $(P=0.001)$ in G3; meanwhile, $\mathrm{CMA}_{3}$ was found to be significantly higher $(P=0.001)$ in $\mathrm{G} 1$; these results contradict the findings of several previous studies $(21,22,24,38)$.

However, the findings of the present study are in agreement with the results obtained by previous studies $(19,21,39,40)$, in that, a positive correlation was found between an alteration in protamine ratio and the presence of DNA damage.

In a meta-analysis, $\mathrm{Ni}$ et al (40) analysed the results of 12 selected studies and determined that the deficiency in protamine measured by $\mathrm{CMA}_{3}$ was significantly associated with DNA fragmentation of sperm whereas the P1/P2 ratio was not associated with DNA fragmentation $(P=0.33)$. By contrast, the present study demonstrated that the correlations between DFI, $\mathrm{CMA}_{3}$, and the P1/P2 ratio were dependent on the values of the protamine ratio $(<0.8 ; 0.8-1.2 ;>1.2)$.

\section{Conclusions}

The results of the study revealed that the protamine ratio (P1/P2) had an effect on DNA integrity and played a crucial role in human sperm quality and function. As a result, it can be used as a biomarker in addition to standard sperm parameters for the selection of sperm in ART treatments.

\section{Conflict of Interests}

Authors declare that they have no conflict of interests.

\section{Ethical Issues}

This study was approved by the Institutional Ethics Committee of Saarland University (under the code of ethics $\mathrm{PHRC} / \mathrm{HC} / 13 / 14)$. All the subjects provided written consent before participation in this study.

\section{Financial Support}

Department of Obstetrics and Gynaecology, Saarland University, Germany.

\section{Acknowledgements}

The authors would like to thank the Department of Obstetrics and Gynaecology, Saarland University, for the financial support.

\section{References}

1. Skakkebaek NE, Jorgensen N, Main KM, et al. Is human fecundity declining? Int J Androl. 2006;29(1):2-11. doi:10.1111/j.1365-2605.2005.00573.x

2. Esteves SC, Zini A, Aziz N, Alvarez JG, Sabanegh ES Jr, Agarwal A. Critical appraisal of World Health Organization's new reference values for human semen characteristics and effect on diagnosis and treatment of subfertile men. Urology. 2012;79(1):16-22. doi:10.1016/j. urology.2011.08.003

3. Dondorp W, de Wert G, Pennings G, et al. Lifestylerelated factors and access to medically assisted reproduction. Hum Reprod. 2010;25(3):578-583. doi:10.1093/humrep/dep458

4. Maggiulli R, Neri QV, Monahan D, et al. What to do when ICSI fails. Syst Biol Reprod Med. 2010;56(5):376387. doi:10.3109/19396361003770321

5. Hotaling JM, Smith JF, Rosen M, Muller CH, Walsh TJ. The relationship between isolated teratozoospermia and clinical pregnancy after in vitro fertilization with or without intracytoplasmic sperm injection: a systematic review and meta-analysis. Fertil Steril. 2011;95(3):11411145. doi:10.1016/j.fertnstert.2010.09.029

6. Hud NV, Vilfan ID. Toroidal DNA condensates: unraveling the fine structure and the role of nucleation in determining size. Annu Rev Biophys Biomol Struct. 2005;34:295-318. doi:10.1146/annurev. biophys.34.040204.144500

7. Brewer L, Corzett M, Balhorn R. Condensation of DNA by spermatid basic nuclear proteins. J Biol Chem. 2002;277(41):38895-38900. doi:10.1074/jbc. M204755200

8. Carrell DT. Epigenetics of the male gamete. Fertil Steril. 2012;97(2):267-274. doi:10.1016/j.fertnstert.2011.12.036

9. Hammoud SS, Nix DA, Hammoud AO, Gibson M, Cairns BR, Carrell DT. Genome-wide analysis identifies 
changes in histone retention and epigenetic modifications at developmental and imprinted gene loci in the sperm of infertile men. Hum Reprod. 2011;26(9):2558-2569. doi:10.1093/humrep/der192

10. Ward WS. Function of sperm chromatin structural elements in fertilization and development. Mol Hum Reprod. 2010;16(1):30-36. doi:10.1093/molehr/gap080

11. Jenkins TG, Carrell DT. The sperm epigenome and potential implications for the developing embryo. Reproduction. 2012;143(6):727-734. doi:10.1530/rep11-0450

12. Aoki VW, Emery BR, Liu L, Carrell DT. Protamine levels vary between individual sperm cells of infertile human males and correlate with viability and DNA integrity. J Androl. 2006;27(6):890-898. doi:10.2164/ jandrol.106.000703

13. Bach O, Glander H-J, Scholz G, Schwarz J. Electrophoretic patterns of spermatozoal nucleoproteins (NP) in fertile men and infertility patients and comparison with NP of somatic cells. Andrologia. 1990;22(3):217-224. doi:10.1111/j.1439-0272.1990.tb01969.x

14. Mengual L, Ballesca JL, Ascaso C, Oliva R. Marked differences in protamine content and P1/P2 ratios in sperm cells from percoll fractions between patients and controls. J Androl. 2003;24(3):438-447. doi:10.1002/j.1939-4640.2003.tb02692.x

15. Garcia-Peiro A, Martinez-Heredia J, Oliver-Bonet M, et al. Protamine 1 to protamine 2 ratio correlates with dynamic aspects of DNA fragmentation in human sperm. Fertil Steril. 2011;95(1):105-109. doi:10.1016/j. fertnstert.2010.06.053

16. Ni K, Steger K, Yang H, Wang H, Hu K, Chen B. Sperm protamine mRNA ratio and DNA fragmentation index represent reliable clinical biomarkers for men with varicocele after microsurgical varicocele ligation. J Urol. 2014;192(1):170-176. doi:10.1016/j.juro.2014.02.046

17. World Health Organization. WHO Laboratory Manual for the Examination and Processing of Human Semen. Geneva, Switzerland: WHO Press; 2010.

18. Kruger TF, Menkveld R, Stander FS, et al. Sperm morphologic features as a prognostic factor in in vitro fertilization. Fertil Steril. 1986;46(6):1118-1123. doi:10.1016/S0015-0282(16)49891-2

19. Hammadeh ME, Hamad MF, Montenarh M, FischerHammadeh C. Protamine contents and P1/P2 ratio in human spermatozoa from smokers and non-smokers. Hum Reprod. 2010;25(11):2708-2720. doi:10.1093/ humrep/deq226

20. Borini A, Tarozzi N, Bizzaro D, et al. Sperm DNA fragmentation: paternal effect on early postimplantation embryo development in ART. Hum Reprod. 2006;21(11):2876-2881. doi:10.1093/humrep/ del251

21. Aoki VW, Moskovtsev SI, Willis J, Liu L, Mullen JB, Carrell DT. DNA integrity is compromised in protaminedeficient human sperm. J Androl. 2005;26(6):741-748. doi:10.2164/jandrol.05063

22. Aoki VW, Liu L, Carrell DT. Identification and evaluation of a novel sperm protamine abnormality in a population of infertile males. Hum Reprod. 2005;20(5):1298-1306. doi:10.1093/humrep/deh798

23. de Yebra L, Ballesca JL, Vanrell JA, Bassas L, Oliva R. Complete selective absence of protamine $\mathrm{P} 2$ in humans. J Biol Chem. 1993;268(14):10553-10557.

24. Carrell DT, Liu L. Altered protamine 2 expression is uncommon in donors of known fertility, but common among men with poor fertilizing capacity, and may reflect other abnormalities of spermiogenesis. J Androl. 2001;22(4):604-610. doi:10.1002/j.1939-4640.2001. tb02220.x

25. Iranpour FG. The effects of protamine deficiency on ultrastructure of human sperm nucleus. Adv Biomed Res. 2014;3:24. doi:10.4103/2277-9175.124666

26. de Yebra L, Ballesca JL, Vanrell JA, Corzett M, Balhorn $\mathrm{R}$, Oliva R. Detection of $\mathrm{P} 2$ precursors in the sperm cells of infertile patients who have reduced protamine P2 levels. Fertil Steril. 1998;69(4):755-759. doi:10.1016/ S0015-0282(98)00012-0

27. de Mateo S, Gazquez C, Guimera M, et al. Protamine 2 precursors (Pre-P2), protamine 1 to protamine 2 ratio (P1/P2), and assisted reproduction outcome. Fertil Steril. 2009;91(3):715-722. doi:10.1016/j.fertnstert.2007.12.047

28. Zhang X, San Gabriel M, Zini A. Sperm nuclear histone to protamine ratio in fertile and infertile men: evidence of heterogeneous subpopulations of spermatozoa in the ejaculate. J Androl. 2006;27(3):414-420. doi:10.2164/ jandrol.05171

29. Montellier E, Boussouar F, Rousseaux S, et al. Chromatin-to-nucleoprotamine transition is controlled by the histone $\mathrm{H} 2 \mathrm{~B}$ variant $\mathrm{TH} 2 \mathrm{~B}$. Genes Dev. 2013;27(15):1680-1692. doi:10.1101/gad.220095.113

30. Laberge RM, Boissonneault G. On the nature and origin of DNA strand breaks in elongating spermatids. Biol Reprod. 2005;73(2):289-296. doi:10.1095/ biolreprod.104.036939

31. Kempisty B, Jedrzejczak P, Jagodzinski PP. [Structure and role of protamines 1 and 2 in spermatogenesis and male infertility]. Ginekol Pol. 2006;77(3):238-245.

32. Evenson DP, Larson KL, Jost LK. Sperm chromatin structure assay: its clinical use for detecting sperm DNA fragmentation in male infertility and comparisons with other techniques. J Androl. 2002;23(1):25-43. doi:10.1002/j.1939-4640.2002.tb02599.x

33. Seli E, Sakkas D. Spermatozoal nuclear determinants of reproductive outcome: implications for ART. Hum Reprod Update. 2005;11(4):337-349. doi:10.1093/ humupd/dmi011

34. Miyagawa Y, Nishimura H, Tsujimura A, et al. Singlenucleotide polymorphisms and mutation analyses of the TNP1 and TNP2 genes of fertile and infertile human male populations. J Androl. 2005;26(6):779-786. doi:10.2164/jandrol.05069

35. Nili HA, Mozdarani H, Aleyasin A. Correlation of sperm DNA damage with protamine deficiency in Iranian subfertile men. Reprod Biomed Online. 2009;18(4):479485. doi:10.1016/S1472-6483(10)60123-x 
36. Manochantr S, Chiamchanya C, Sobhon P. Relationship between chromatin condensation, DNA integrity and quality of ejaculated spermatozoa from infertile men. Andrologia. 2012;44(3):187-199. doi:10.1111/j.14390272.2010.01128.x

37. Aoki VW, Carrell DT. Human protamines and the developing spermatid: their structure, function, expression and relationship with male infertility. Asian J Androl. 2003;5(4):315-324.

38. Castillo J, Simon L, de Mateo S, Lewis S, Oliva R. Protamine/DNA ratios and DNA damage in native and density gradient centrifuged sperm from infertile patients. J Androl. 2011;32(3):324-332. doi:10.2164/ jandrol.110.011015

39. Torregrosa N, Dominguez-Fandos D, Camejo MI, et al. Protamine 2 precursors, protamine 1/protamine 2 ratio, DNA integrity and other sperm parameters in infertile patients. Hum Reprod. 2006;21(8):2084-2089. doi:10.1093/humrep/del114

40. Ni K, Spiess AN, Schuppe HC, Steger K. The impact of sperm protamine deficiency and sperm DNA damage on human male fertility: a systematic review and metaanalysis. Andrology. 2016;4(5):789-799. doi:10.1111/ andr.12216

(C) 2018 The Author (s); This is an open-access article distributed under the terms of the Creative Commons Attribution License (http://creativecommons.org/licenses/by/4.0), which permits unrestricted use, distribution, and reproduction in any medium, provided the original work is properly cited. 